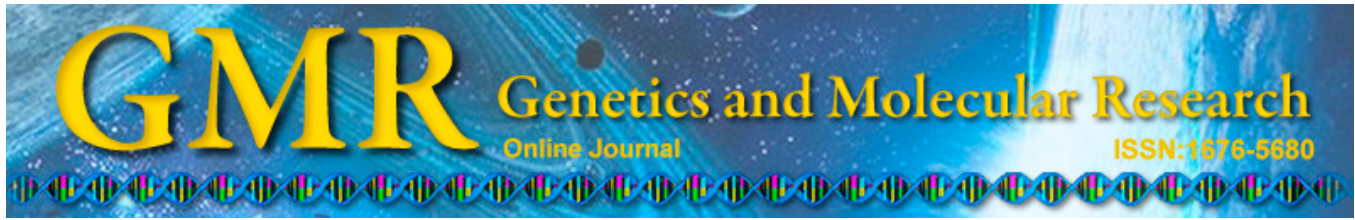

\title{
Mutational analysis of podocyte genes in children with sporadic steroid-resistant nephrotic syndrome
}

\author{
D.N. Feng ${ }^{1 *}$, Y.H. Yang ${ }^{1 *}$, D.J. Wang ${ }^{1 *}$, D.C. Meng ${ }^{1 *}$, R. Fu ${ }^{1}$, J.J. Wang ${ }^{1}$ \\ and Z.H. Yu ${ }^{1,2,3}$ \\ ${ }^{1}$ Department of Pediatrics, Fuzhou Dongfang Hospital, Fuzhou, Fujian, China \\ ${ }^{2}$ Department of Pediatrics, Fuzhou Clinical Medical College, \\ Fujian Medical University, Fuzhou, Fujian, China \\ ${ }^{3}$ Department of Pediatrics, Affiliated Dongfang Hospital, Xiamen University, \\ Fuzhou, Fujian, China \\ *These authors contributed equally to this study. \\ Corresponding author: Z.H. Yu \\ E-mail: zihuayu@vip.sina.com
}

Genet. Mol. Res. 13 (4): 9514-9522 (2014)

Received October 17, 2013

Accepted May 4, 2014

Published November 11, 2014

DOI http://dx.doi.org/10.4238/2014.November.11.16

\begin{abstract}
Recent studies have demonstrated that mutations in 4 podocyte genes, NPHS1, NPHS2, CD2AP, and WT1, are associated with the pathogenesis of steroid-resistant nephrotic syndrome (SRNS). Systematic investigation of all 4 genes for sporadic SRNS in China has not been performed. We examined 10 Chinese children with sporadic SRNS who showed no response to immunosuppressive agents and 20 SRNS controls who exhibited a response to prolonged steroid or immunosuppressive treatment and achieved complete remission. We analyzed mutations in the 4 podocyte genes, NPHS1, NPHS2, CD2AP, and WT1. Mutational analysis was performed using polymerase chain reaction and direct sequencing. Of the 10 SRNS children who showed no response to immunosuppressive agents, the compound heterozygous NPHS1 mutations $2677 \mathrm{~A}>\mathrm{G}$ (T893A)
\end{abstract}


and $* 142 \mathrm{~T}>\mathrm{C}$ were identified in 1 patient, while a heterozygous mutation in $W T 1,1180 \mathrm{C}>\mathrm{T}(\mathrm{R} 394 \mathrm{~W})$, was found in another patient. Of the 20 SRNS children showing complete remission who responded to prolonged steroid therapy or immunosuppressive agents, 4 heterozygous NPHS1 mutations, $928 \mathrm{G}>\mathrm{A}$, IVS8+30C $>\mathrm{T}$, IVS21+14G $>$ A, and IVS25-23C $>$ T, were identified in 4 patients and a heterozygous $C D 2 A P$ mutation, IVS7-135G $>A$, was identified in 1 patient. Our results indicate the necessity of genetic examination for mutations in podocyte genes in Chinese SRNS children who show no response to immunosuppressive agents.

Key words: Immunosuppressive agents; Mutation; Podocyte genes; Steroid-resistant nephrotic syndrome; Steroid treatment

\section{INTRODUCTION}

Idiopathic nephrotic syndrome (NS) is a very common childhood glomerular disease. It is characterized by the association of gross proteinuria with hypoalbuminemia, edema, and hyperlipidemia, a condition that typically requires a prolonged course of steroids or immunosuppressive treatment. Approximately $10 \%$ of patients do not respond to corticosteroids and are at risk for additional renal complications of NS and the development of end-stage renal disease (ESRD) (Benoit et al., 2010). Recent studies have demonstrated that mutations in a number of podocyte genes, including NPHS1, NPHS2, and $C D 2 A P$, are associated with the pathogenesis of steroid-resistant nephrotic syndrome (SRNS) (Boute et al., 2000; Ruf et al., 2004b; Löwik et al., 2007; Philippe et al., 2008). NPHS1, NPHS2, and CD2AP code for structural elements of the slit diaphragm in the glomerular filtration barrier and have been identified as the causative genes in autosomalrecessive (AR) SRNS. When these genes are mutated, patients with AR SRNS can show resistance to steroids and immunosuppressive agents (Boute et al., 2000; Ruf et al., 2004a; Ehrich et al., 2007; Löwik et al., 2007; Philippe et al., 2008; Büscher et al., 2010). Mutations in NPHS1, which is located on chromosome 19q13.1 and contains 29 exons that encode nephrin, cause not only congenital NS of the Finnish type but also childhoodonset SRNS (Kestilä et al., 1998; Philippe et al., 2008). Mutations in NPHS2, which is located on chromosome 1q25-31 and contains 8 exons that encode podocin, are associated with AR SRNS (Boute et al., 2000). Mutations in CD2AP, which contains 18 exons and encodes CD2AP, have been identified in sporadic NS and focal segmental glomerulosclerosis (FSGS) (Löwik et al., 2007; Gigante et al., 2009). The WT1 gene is located on chromosome $11 \mathrm{p} 13$, contains 10 exons, and encodes a zinc finger transcription factor involved in kidney and gonadal development (Call et al., 1990). Mutations in WT1 have been shown to cause Denys-Drash syndrome (DDS), Frasier syndrome (FS), and isolated SRNS (Machuca et al., 2009; Benoit et al., 2010). DDS is characterized by the association of early onset NS and diffuse mesangial sclerosis, which rapidly progresses to ESRD, XY pseudohermaphrodism, and Wilms' tumor (Ruf et al., 2004b; Benoit et al., 2010). Incomplete DDS is characterized as NS associated with Wilms' tumor or XY pseudohermaphro- 
dism (Schumacher et al., 1998). FS is also characterized by male pseudohermaphrodism as well as nephropathy (Ruf et al., 2004b; Benoit et al., 2010). Most SRNS patients with mutations in the podocyte genes NPHS1, NPHS2, CD2AP, and WT1 are also resistant to immunosuppressive agents (Boute et al., 2000; Ruf et al., 2004a,b; Löwik et al., 2007; Philippe et al., 2008; Benoit et al., 2010; Büscher et al., 2010; Li et al., 2010; Megremis et al., 2011; Stefanidis and Querfeld, 2011).

Classification of SRNS can be modified by the results of gene analysis. Therefore, understanding causative mutations in podocyte genes in Chinese children with SRNS is important; however, a systematic investigation has not been performed. To clarify the role of these genetic mutations, all exons and exon-intron boundaries for all 4 genes were analyzed in 10 Chinese SRNS children who showed no response to immunosuppressive agents.

\section{MATERIAL AND METHODS}

\section{Subjects}

This study included children $(\mathrm{N}=10)$ who were suffering from sporadic SRNS. Inclusion criteria included: 1) children of non-consanguineous marriages with onset between 3 months and 18 years of age; 2) no family history of renal diseases; 3 ) no response to immunosuppressive agents; 4) renal histology showed changes of focal segmental glomerulosclerosis, minimal-change NS, or mesangial proliferative glomerulonephritis; and 5) other systemic diseases were excluded following clinical and laboratory examinations. The control group included SRNS children $(\mathrm{N}=20)$ who responded to either prolonged steroid therapy or immunosuppressive agents. We also studied unrelated adult volunteers $(\mathrm{N}=50)$ with normal urinalyses as controls.

NS was diagnosed based on urinary protein excretion $>50 \mathrm{mg} \cdot \mathrm{kg}^{-1} \cdot \mathrm{day}^{-1}$ with hypoalbuminemia $<25 \mathrm{~g} / \mathrm{L}$. Complete remission was defined as normal urinalysis or trace protein on dipstick analysis for 3 consecutive days and normalization of serum albumin levels $(>35 \mathrm{~g} / \mathrm{L})$. Partial remission was defined as the resolution of edema, proteinuria from $4-40 \mathrm{mg} \cdot \mathrm{m}^{-2} \cdot \mathrm{h}^{-1}$, and normalization of serum albumin. Steroid resistance was defined as a failure of induction of complete remission after 4 weeks of standard therapy with prednisone $\left(2 \mathrm{mg} \cdot \mathrm{kg}^{-1} \cdot \mathrm{day}^{-1}\right.$, given in 3 divided doses, maximum $60 \mathrm{mg}$ /day). Patients with late steroid resistance were excluded from the study. ESRD was defined as a glomerular filtration rate below $10 \mathrm{~mL} / \mathrm{min}$ per 1.73 $\mathrm{m}^{2}$, or the necessity of any renal replacement therapy.

Treatment with cyclophosphamide, cyclosporine, mycophenolate mophetil, or tacrolimus of most patients with no response to steroids was determined by disease activity. This study was approved by the Ethics Committee of Fuzhou Dongfang Hospital (China). Informed consent was obtained from patients or their parents.

\section{Mutational analysis}

Mutational analysis was carried out using blood samples. Genomic DNA was extracted from peripheral blood leukocytes using an EZNASE Blood DNA Kit (OMEGA 
Bio-Tek, Inc., Norcross, GA, USA) according to the manufacturer protocol. Mutational analysis was performed by direct sequencing of all 29 exons of NPHS1, all 8 exons of NPHS2, all 18 exons of $C D 2 A P$, and all 10 exons of $W T 1$. Exons were amplified by polymerase chain reaction (PCR) using intron-flanking primers as described previously (Lenkkeri et al., 1999; Yu et al., 2005; Li et al., 2010; Meng et al., 2011), except for 3 sets of primers that amplified exons 6, 9, and 16 of $C D 2 A P$. Primers were designed using the Primer 3 software based on the human genomic sequence (NT_007592.15 and NM_012120.2). PCR primers for amplifying exons 6, 9, and 16 were as follows: exon 6, TGTCAAGCGTTTTGTGATTCT and CTGTGCTAACTAAAAACCCTAAAG; exon 9, TGGGAGACCAAATCAAGAGG and CAGTCGAGAAAGAAACAAAGGAA; exon 16, CTGTTACATTCTTGCCCCTGTTTCA and TACCACACCCAGCCACAGATTAGAT. PCR products were visualized by $1.5 \%(\mathrm{w} / \mathrm{v})$ agarose gel electrophoresis and sequenced using an ABI 3730XL DNA Analyzer (Applied Biosystems, Foster City, CA, USA). Mutations were confirmed by sequencing in both directions and by repeated amplification and sequencing. Genomic DNA from 50 healthy controls was used to confirm mutations and to exclude DNA polymorphisms.

\section{RESULTS}

\section{Clinical data for patients with SRNS}

The clinical findings of the 10 SRNS children who showed no response to immunosuppressive agents and 20 SRNS controls are summarized in Table 1 . Of the 10 patients ( 6 males, 4 females) who experienced no sustained reduction in proteinuria, the average age of disease onset was 53.7 months (range: 8-147 months); renal biopsy, which was available for 3 patients, revealed FSGS, mesangial proliferative glomerulonephritis (MsPGN), and minimal change nephrotic syndrome (MCNS). Of the 20 SRNS controls (15 males, 5 females) who exhibited a response to prolonged steroid or immunosuppressive treatment and achieved complete remission, the average age of onset was 59 months (range: 15-149 months); renal biopsy, which was available for 9 patients, revealed MsPGN in 5 patients, FSGS in 2 patients, MCNS in 1 patient, and membranous nephropathy in 1 patient. One child, who did not show a sustained reduction in proteinuria following prolonged steroid treatment, progressed to ESRD within 6 months after disease onset. None of the 20 SRNS controls with complete response reached ESRD during the follow-up time of 8.282.7 months.

\section{DNA sequence analysis}

Six NPHS1 variants, $928 \mathrm{G}>\mathrm{A}, \quad 2677 \mathrm{~A}>\mathrm{G}, \quad$ IVS $8+30 \mathrm{C}>\mathrm{T}$, IVS $21+14 \mathrm{G}>\mathrm{A}$, IVS25-23C $>\mathrm{T}$, and $* 142 \mathrm{~T}>\mathrm{C}$, were detected in 5 patients (Figure 1 and Table 2). Two heterozygous $C D 2 A P$ variants, IVS7-135G $>A$ and IVS13-137G $>A$, were detected in 2 patients (Figure 1 and Table 2). One heterozygous WT1 mutation, 1180C $>$ T, was identified in 1 patient (Figure 1 and Table 2). None of the above variants were found in the 50 healthy controls. No mutation in the NPHS2 gene was found in any patient. 
Table 1. Clinical data of 30 patients with sporadic steroid-resistant nephrotic syndrome.

\begin{tabular}{|c|c|c|c|c|c|c|c|}
\hline Patient & Gender & Karyotype & $\begin{array}{l}\text { Age at disease onset } \\
\text { (months) }\end{array}$ & Renal biopsy & $\begin{array}{c}\text { Follow-up } \\
\text { period (months) }\end{array}$ & Therapy and response & $\begin{array}{l}\text { ESRD after disease } \\
\text { onset (months) }\end{array}$ \\
\hline 1 & $\mathrm{~F}$ & $46, X Y$ & 14 & ND & 6.0 & GC (NR) & 6 \\
\hline 2 & M & ND & 96 & MCNS & 44.7 & $\mathrm{GC}, \mathrm{MMF}(\mathrm{NR})$ & $\mathrm{N}$ \\
\hline 3 & M & ND & 147 & ND & 8.4 & GC, CTX, MMF (NR) & $\mathrm{N}$ \\
\hline 4 & M & $46, X Y$ & 19 & ND & 33.3 & GC, CsA, MMF (NR) & $\mathrm{N}$ \\
\hline 5 & M & $46, X Y$ & 8 & ND & 7.9 & GC, CTX (NR) & $\mathrm{N}$ \\
\hline 6 & $\mathrm{M}$ & ND & 90 & MsPGN & 11.0 & $\mathrm{GC}, \mathrm{CsA}(\mathrm{NR})$ & $\mathrm{N}$ \\
\hline 7 & $\mathrm{~F}$ & ND & 58 & FSGS & 18.7 & GC, CsA (NR) & $\mathrm{N}$ \\
\hline 8 & $\mathrm{~F}$ & ND & 34 & ND & 12.2 & GC, CsA, TAC (NR) & $\mathrm{N}$ \\
\hline 9 & $\mathrm{~F}$ & ND & 28 & ND & 14.0 & GC, CsA, TAC (NR) & $\mathrm{N}$ \\
\hline 10 & $\mathrm{M}$ & ND & 43 & ND & 10.4 & $\mathrm{GC}, \mathrm{CsA}(\mathrm{NR})$ & $\mathrm{N}$ \\
\hline 11 & M & ND & 63 & ND & 26.7 & GC (R) & $\mathrm{N}$ \\
\hline 12 & M & ND & 31 & ND & 9.6 & GC (R) & $\mathrm{N}$ \\
\hline 13 & M & ND & 24 & ND & 26.0 & $\mathrm{GC}(\mathrm{R})$ & $\mathrm{N}$ \\
\hline 14 & $\mathrm{M}$ & ND & 44 & MsPGN & 10.3 & $\mathrm{GC}(\mathrm{R})$ & $\mathrm{N}$ \\
\hline 15 & $\mathrm{M}$ & ND & 32 & ND & 74.7 & $\mathrm{GC}(\mathrm{R})$ & $\mathrm{N}$ \\
\hline 16 & $\mathrm{M}$ & ND & 66 & ND & 10.1 & GC (R) & $\mathrm{N}$ \\
\hline 17 & $\mathrm{~F}$ & ND & 15 & ND & 27.0 & GC (R) & $\mathrm{N}$ \\
\hline 18 & $\mathrm{~F}$ & ND & 80 & ND & 8.2 & GC (R) & $\mathrm{N}$ \\
\hline 19 & M & ND & 118 & MsPGN & 24.8 & GC (R) & $\mathrm{N}$ \\
\hline 20 & M & ND & 42 & FSGS & 31.3 & $\mathrm{GC}, \mathrm{CsA}(\mathrm{R})$ & $\mathrm{N}$ \\
\hline 21 & $\mathrm{~F}$ & $46, \mathrm{XX}$ & 99 & $\mathrm{MN}$ & 36.9 & $\mathrm{GC}, \mathrm{CsA}(\mathrm{R})$ & $\mathrm{N}$ \\
\hline 22 & $\mathrm{~F}$ & ND & 138 & MsPGN & 38.6 & $\mathrm{GC}, \mathrm{CsA}(\mathrm{R})$ & $\mathrm{N}$ \\
\hline 23 & M & ND & 18 & ND & 26.1 & $\mathrm{GC}, \mathrm{CsA}(\mathrm{R})$ & $\mathrm{N}$ \\
\hline 24 & M & ND & 16 & ND & 28.6 & $\mathrm{GC}, \mathrm{CsA}(\mathrm{R})$ & $\mathrm{N}$ \\
\hline 25 & M & ND & 56 & FSGS & 55.2 & $\mathrm{GC}, \mathrm{CsA}(\mathrm{R})$ & $\mathrm{N}$ \\
\hline 26 & M & ND & 108 & MCNS & 42.5 & $\mathrm{GC}, \mathrm{CsA}(\mathrm{R})$ & $\mathrm{N}$ \\
\hline 27 & M & ND & 149 & MsPGN & 36.4 & GC, CsA (R) & $\mathrm{N}$ \\
\hline 28 & $\mathrm{~F}$ & ND & 35 & MsPGN & 82.7 & GC (R) & $\mathrm{N}$ \\
\hline 29 & M & ND & 22 & ND & 22.3 & $\mathrm{GC}, \mathrm{CsA}(\mathrm{R})$ & $\mathrm{N}$ \\
\hline 30 & M & ND & 24 & ND & 14.4 & $\mathrm{GC}, \mathrm{CsA}(\mathrm{R})$ & $\mathrm{N}$ \\
\hline
\end{tabular}

ESRD = end-stage renal disease; $\mathrm{ND}=$ not determined; MCNS = minimal-change nephrotic syndrome; MsPGN $=$ mesangial proliferative glomerulonephritis; FSGS = focal segmental glomerulosclerosis; $\mathrm{MN}=\mathrm{membranous}$ nephropathy; $\mathrm{GC}=$ glucocorticosteroid; $\mathrm{NR}=$ not remission; $\mathrm{MMF}=$ mycophenolate mofetil; $\mathrm{CTX}=$ cyclophosphamide; $\mathrm{CsA}=$ cyclosporine; $\mathrm{TAC}=$ tacrolimus; $\mathrm{R}=$ complete remission; $\mathrm{N}=$ not progressed to $\mathrm{ESRD}$.
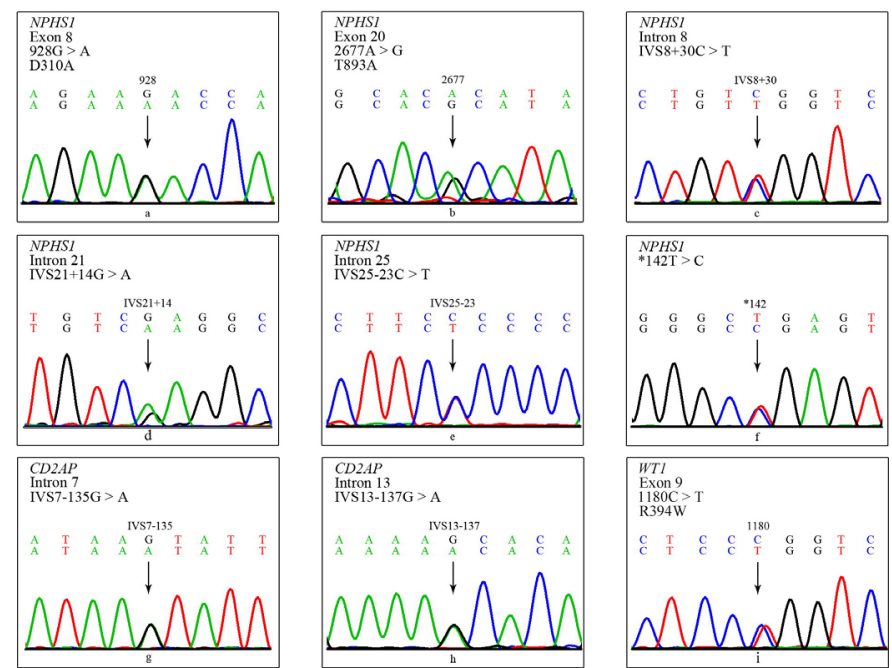

Figure 1. Mutations in podocyte genes NPHS1, CD2AP, and WT1 were identified by sequencing in 8 patients. (a.f.) Chromatograms show 6 NPHS1 mutations: 928G $>$ A, 2677A $>$ G, IVS8+30C $>$ T, IVS21+14G $>$ A, IVS25-23C $>$ T, and $* 142 \mathrm{~T}>\mathrm{C}$, respectively. (g. h.) Chromatograms revealed 2 CD2AP mutations: IVS7-135G $>\mathrm{A}$ and IVS13$137 \mathrm{G}>$ A. (i.) Chromatogram revealed $1 \mathrm{WT1}$ mutation: $1180 \mathrm{C}>\mathrm{T}$. Arrows indicate mutant positions. 
Table 2. Mutations detected in 8 patients with sporadic steroid-resistant nephrotic syndrome.

\begin{tabular}{|c|c|c|c|c|c|c|c|c|c|}
\hline \multirow[t]{2}{*}{ Patient } & \multicolumn{3}{|c|}{ NPHS1 } & \multicolumn{3}{|c|}{$C D 2 A P$} & \multicolumn{3}{|c|}{$W T 1$} \\
\hline & $\begin{array}{l}\text { Nucleotide } \\
\text { substitution }\end{array}$ & $\begin{array}{l}\text { Effect on } \\
\text { protein }\end{array}$ & $\begin{array}{l}\text { Mutation } \\
\text { status }\end{array}$ & $\begin{array}{l}\text { Nucleotide } \\
\text { substitution }\end{array}$ & $\begin{array}{l}\text { Effect on } \\
\text { protein }\end{array}$ & $\begin{array}{l}\text { Mutation } \\
\text { status }\end{array}$ & $\begin{array}{l}\text { Nucleotide } \\
\text { substitution }\end{array}$ & $\begin{array}{l}\text { Effect on } \\
\text { protein }\end{array}$ & $\begin{array}{l}\text { Mutation } \\
\text { status }\end{array}$ \\
\hline 1 & & & & & & & $1180 \mathrm{C}>\mathrm{T}$ & R394W & het \\
\hline 2 & & & & IVS13-137G $>A$ & & het & & & \\
\hline 7 & $\begin{array}{l}2677 \mathrm{~A}>\mathrm{G} \\
* 142 \mathrm{~T}>\mathrm{C}\end{array}$ & T893A & $\begin{array}{l}\text { het } \\
\text { het }\end{array}$ & & & & & & \\
\hline 12 & IVS $21+14 \mathrm{G}>\mathrm{A}$ & & het & & & & & & \\
\hline 13 & $928 \mathrm{G}>\mathrm{A}$ & D310N & het & & & & & & \\
\hline 16 & IVS $8+30 \mathrm{C}>\mathrm{T}$ & & het & & & & & & \\
\hline 21 & IVS25-23C $>T$ & & het & & & & & & \\
\hline 25 & & & & IVS7-135G $>A$ & & het & & & \\
\hline
\end{tabular}

*The first nucleotide of the ATG translation codon is considered $n t+1$. Patient numbers correspond to the numbers in Table 1. het = heterozygous mutation.

\section{DISCUSSION}

Mutational analysis of 4 podocyte genes (NPHS1, NPHS2, CD2AP, and WT1) was performed on 10 Chinese SRNS children who showed no response to immunosuppressive agents, using PCR and direct sequencing. Pathogenic mutations were identified in 2 of the 10 patients $(20 \%)$ who experienced no sustained reduction in proteinuria following prolonged steroid or immunosuppressive agent treatment. No mutations were detected in the 20 SRNS controls who achieved complete remission following prolonged steroid or immunosuppressive agent treatment. The data suggest that mutational analysis of podocyte genes should be performed on SRNS patients who show no response to either prolonged steroid or immunosuppressive agent treatment.

As shown in Table 2, compound heterozygous variants of NPHS1, 2677A $>\mathrm{G}$ and $* 142 \mathrm{~T}>\mathrm{C}$, were identified in patient 7 , while the heterozygous variant of $W T 1,1180 \mathrm{C}>\mathrm{T}$, was identified in patient 1 . Variants $2677 \mathrm{~A}>\mathrm{G}$ and $* 142 \mathrm{~T}>\mathrm{C}$ were not found in the 50 controls, indicating that these are NPHS1 mutations. Several lines of evidence suggest that the NPHS1 mutation $2677 \mathrm{~A}>\mathrm{G}$ is pathogenic. First, the NPHS1 mutation of $2677 \mathrm{~A}>\mathrm{G}$ leads to a threonine to alanine substitution at codon 893 of nephrin (T893A). Second, sequence conservation of the 2677 nucleotide in human NPHS1 mRNA, counted from the beginning of the start codon, has been established by alignment analysis of Homo sapiens (GenBank NM_004646.3), Pan troglodytes (GenBank XM_524228.4), Macaca mulatta (GenBank XM_001112314.1), Bos taurus (GenBank NM_001192512.1), Canis lupus familiaris (GenBank XM_541685.3), Rattus norvegicus (GenBank NM_022628.1), Mus musculus (GenBank NM_019459.2), and Xenopus laevis (GenBank NM_001095706.1) NPHS1 mRNA. Third, alignment analysis of nephrin in humans (GenBank NP_004637.1), P. troglodytes (GenBank XP_524228.3), M. mulatta (GenBank XP_001112314.1), B. taurus (GenBank NP_001179441.1), C. lupus familiaris (GenBank XP_541685.2), and X. laevis (GenBank NP_001089175.1) has also shown that the 893rd amino acid of human nephrin is threonine, while the corresponding amino acids in rats (GenBank NP_072150.1) and mice (GenBank NP_062332.2) are isoleucine and lysine, respectively. All 3 amino acids with polar side chains are hydrophilic. Finally, nephrin is a major component of the zipper-like isoporous filter structure for assembly into the slit diaphragm and is crucial for the selective filtration function of the kidneys (Ruotsalainen et al., 1999). Amino acid residues located in Ig-like modules of nephrin are critical for the function of the 
modules (Lenkkeri et al., 1999). The missense mutant T893A affects the conservative residues of the 8 nephrin Ig domains. Whether the other heterozygous NPHS1 mutation, ${ }^{*} 142 \mathrm{~T}>\mathrm{C}$, in the 3 '-untranslated region actually causes disease remains unknown. Patient 7 was clinically diagnosed with NS at the age of 58 months; she failed to respond to either steroid or cyclosporin A treatment, and her renal pathology showed changes of FSGS. These clinical features were similar to those of patients with homozygous mutations or compound heterozygous mutations, or a heterozygous pathogenic mutation, in their NPHS1 genes, as reported previously (Heeringa et al., 2008; Philippe et al., 2008; Caridi et al., 2009; Santín et al., 2009). It is likely that the compound heterozygous state of the NPHS1 mutations caused development of SRNS in patient 7 .

The $W T 1$ variant, $1180 \mathrm{C}>\mathrm{T}$, in patient 1 was absent in the 50 normal controls, indicating that it is a WT1 mutation. Having the $1180 \mathrm{C}>\mathrm{T}$ variant results in the substitution of arginine with tryptophan at codon 394 of WT1 (R394W). Karyotype analysis of patient 1 showed 46 chromosomes; she was an XY phenotypic girl, and ultrasound examination showed no renal tumors. Patient 1 was diagnosed at the age of 14 months with DDS and failed to respond to steroids. She reached ESRD at the age of 20 months. Previous studies have reported that the WT1 mutation R394W can cause DDS, FS, or isolated SRNS (Call et al., 1990; Gigante et al., 2009); therefore, we considered this mutation to be responsible for the phenotype observed in patient 1.

A heterozygous mutation of $C D 2 A P$ of IVS13-137G $>A$ with no identified pathogenicity was detected in patient 2, who carried no mutations in NPHS1, NPHS2, or WT1. Patient 2 presented NS at 96 months of age and failed to respond to steroids. His renal biopsy showed MCNS. He received treatment with mycophenolate mophetil, but did not reach remission of proteinuria. Whether the heterozygous mutation of $C D 2 A P$ is a rare $C D 2 A P$ polymorphism or is a pathogenic $C D 2 A P$ mutation could not be determined because of the unavailability of a functional assay.

In our study, we found pathogenic mutations in the podocyte genes NPHS1, NPHS2, $C D 2 A P$, and $W T 1$ in $20 \%$ of the 10 SRNS patients who did not respond to either steroids or immunosuppressive agents. Our results are consistent with those of Löwik et al. (2008) who identified mutations in the podocyte genes NPHS1, NPHS2, CD2AP, and WT1 in 4 (26.7\%) of 15 SRNS patients who showed no response to prolonged steroid or immunosuppressive treatment. In addition, Santín et al. (2011) detected mutations in podocyte genes in NPHS1, NPHS2, CD2AP, and WT1 in 7 (22.2\%) of 36 SRNS patients who showed no response to prolonged steroid or immunosuppressive treatment.

In the 20 SRNS controls with remission following prolonged steroid or immunosuppressive treatment, each patient (Table 2 ; patients $12,13,16$, and 21) carried only 1 heterozygous mutation in NPHS1. One patient (Table 2, patient 25) carried only 1 heterozygous mutation in CD2AP. However, from a genetic perspective, NPHS1 mutations are responsible for the autosomal recessive form of SRNS and should produce an evident phenotype in either homozygosity or compound heterozygosity, and an NPHS1 heterozygous mutation cannot explain the pathogenesis. In contrast to the SRNS patients with homozygous or compound heterozygous mutations, all 4 patients with heterozygous mutations in NPHS1 responded to prolonged steroid or immunosuppressive treatment and went into remission. Patient 25 was found to carry 1 heterozygous mutation in the $C D 2 A P$ gene, IVS7-135G $>A$, which showed no effect upon altering a splice site using Splice Site Prediction by Neural Network (http://www. fruitfly.org/seq_tools/splice.html), suggesting that IVS7-135G $>$ A is not a causative mutation. 
Patient 25 was diagnosed at 56 months of age with NS and failed to respond to steroids, but went into remission after receiving cyclosporin A. This cannot be explained based on inherited structural defects of the glomerular filtration barrier.

In summary, we identified mutations in the podocyte genes in 2 of 10 patients who were resistant to both steroids and immunosuppressive agents. Our investigation supports the necessity for genetic examination of mutations in podocyte genes in Chinese SRNS children who do not respond to either steroid or immunosuppressive agent treatment.

\section{ACKNOWLEDGMENTS}

The authors would like to thank the patients and their families for participating in this study and Professor Jie Ding for help in securing grant support for the study. Research supported by grants from the National Nature Science Foundation of China (\#81270766), the Nature Science Foundation of Fujian Province of China (\#2012J01405), and the Key Project of Social Development of Fujian Province of China (\#2013Y0072).

\section{REFERENCES}

Benoit G, Machuca E and Antignac C (2010). Hereditary nephrotic syndrome: a systematic approach for genetic testing and a review of associated podocyte gene mutations. Pediatr. Nephrol. 25: 1621-1632.

Boute N, Gribouval O, Roselli S, Benessy F, et al. (2000). NPHS2, encoding the glomerular protein podocin, is mutated in autosomal recessive steroid-resistant nephrotic syndrome. Nat. Genet. 24: 349-354.

Büscher AK, Kranz B, Buscher R, Hildebrandt F, et al. (2010). Immunosuppression and renal outcome in congenital and pediatric steroid-resistant nephrotic syndrome. Clin. J. Am. Soc. Nephrol. 5: 2075-2084.

Call KM, Glaser T, Ito CY, Buckler AJ, et al. (1990). Isolation and characterization of a zinc finger polypeptide gene at the human chromosome 11 Wilms' tumor locus. Cell 60: 509-520.

Caridi G, Gigante M, Ravani P, Trivelli A, et al. (2009). Clinical features and long-term outcome of nephrotic syndrome associated with heterozygous NPHS1 and NPHS2 mutations. Clin. J. Am. Soc. Nephrol. 4: 1065-1072.

Ehrich JH, Geerlings C, Zivicnjak M, Franke D, et al. (2007). Steroid-resistant idiopathic childhood nephrosis: overdiagnosed and undertreated. Nephrol. Dial. Transplant. 22: 2183-2193.

Gigante M, Pontrelli P, Montemurno E, Roca L, et al. (2009). CD2AP mutations are associated with sporadic nephrotic syndrome and focal segmental glomerulosclerosis (FSGS). Nephrol. Dial. Transplant. 24: 1858-1864.

Heeringa SF, Vlangos CN, Chernin G, Hinkes B, et al. (2008). Thirteen novel NPHS1 mutations in a large cohort of children with congenital nephrotic syndrome. Nephrol. Dial. Transplant. 23: 3527-3533.

Kestilä M, Lenkkeri U, Mannikko M, Lamerdin J, et al. (1998). Positionally cloned gene for a novel glomerular protein nephrin - is mutated in congenital nephrotic syndrome. Mol. Cell 1: 575-582.

Lenkkeri U, Mannikko M, McCready P, Lamerdin J, et al. (1999). Structure of the gene for congenital nephrotic syndrome of the Finnish type (NPHS1) and characterization of mutations. Am. J. Hum. Genet. 64: 51-61.

Li J, Ding J, Zhao D, Yu Z, et al. (2010). WT1 gene mutations in Chinese children with early onset nephrotic syndrome. Pediatr. Res. 68: 155-158.

Löwik M, Groenen PJ, Pronk I, Lilien MR, et al. (2007). Focal segmental glomerulosclerosis in a patient homozygous for a CD2AP mutation. Kidney Int. 72: 1198-1203.

Löwik M, Levtchenko E, Westra D, Groenen P, et al. (2008). Bigenic heterozygosity and the development of steroidresistant focal segmental glomerulosclerosis. Nephrol. Dial. Transplant. 23: 3146-3151.

Machuca E, Benoit G and Antignac C (2009). Genetics of nephrotic syndrome: connecting molecular genetics to podocyte physiology. Hum. Mol. Genet. 18: R185-R194.

Megremis S, Mitsioni A, Fylaktou I, Tzeli SK, et al. (2011). Broad and unexpected phenotypic expression in Greek children with steroid-resistant nephrotic syndrome due to mutations in the Wilms' tumor 1 (WT1) gene. Eur. J. Pediatr. 170: 1529-1534.

Meng DC, Wang DJ, Yu ZH, Fu R, et al. (2011). Mutational analysis of CD2AP and NPHS1 gene in 3 families from Southern Chinese Han ethnic group with steroid-resistant nephrotic syndrome. J. Appl. Clin. Pediatr. 26: 329-344. 
Philippe A, Nevo F, Esquivel EL, Reklaityte D, et al. (2008). Nephrin mutations can cause childhood-onset steroidresistant nephrotic syndrome. J. Am. Soc. Nephrol. 19: 1871-1878.

Ruf RG, Lichtenberger A, Karle SM, Haas JP, et al. (2004a). Patients with mutations in NPHS2 (podocin) do not respond to standard steroid treatment of nephrotic syndrome. J. Am. Soc. Nephrol. 15: 722-732.

Ruf RG, Schultheiss M, Lichtenberger A, Karle SM, et al. (2004b). Prevalence of WT1 mutations in a large cohort of patients with steroid-resistant and steroid-sensitive nephrotic syndrome. Kidney Int. 66: 564-570.

Ruotsalainen V, Ljungberg P, Wartiovaara J, Lenkkeri U, et al. (1999). Nephrin is specifically located at the slit diaphragm of glomerular podocytes. Proc. Natl. Acad. Sci. U. S. A. 96: 7962-7967.

Santín S, Garcia-Maset R, Ruiz P, Gimenez I, et al. (2009). Nephrin mutations cause childhood- and adult-onset focal segmental glomerulosclerosis. Kidney Int. 76: 1268-1276.

Santín S, Bullich G, Tazon-Vega B, Garcia-Maset R, et al. (2011). Clinical utility of genetic testing in children and adults with steroid-resistant nephrotic syndrome. Clin. J. Am. Soc. Nephrol. 6: 1139-1148.

Schumacher V, Scharer K, Wuhl E, Altrogge H, et al. (1998). Spectrum of early onset nephrotic syndrome associated with WT1 missense mutations. Kidney Int. 53: 1594-1600.

Stefanidis CJ and Querfeld U (2011). The podocyte as a target: cyclosporin A in the management of the nephrotic syndrome caused by WT1 mutations. Eur. J. Pediatr. 170: 1377-1383.

Yu Z, Ding J, Huang J, Yao Y, et al. (2005). Mutations in NPHS2 in sporadic steroid-resistant nephrotic syndrome in Chinese children. Nephrol. Dial. Transplant. 20: 902-908. 